\title{
The British Museum Catalogue as the Basis of an Universal Catalogue.'
}

BUT little has of late been heard of the proposed Universal Catalogue of Literature, which was a favourite subject of discussion some years ago. The cause may partly be the loss of some like Sir Henry Cole and the late lamented Mr. Ernest Thomas, who were especially interested in the project; but must be mainly, I should think, the growing perception of the difficulty of the undertaking. It could no doubt be performed by a sufficiently numerous body of competent persons, working under efficient control, guided by fixed rules, and influenced by such consideration in the shape of salary and pension as to induce them to devote their lives to it. There is not, however, the least probability of the endowment of such a college of cataloguers. If the universal catalogue is ever to be attained, we must submit to proceed by gradual approaches, and to be content with something very far short of perfection in the execution of the work. We must take the printed catalogue of that library which most nearly approaches universality as a basis, and we must appeal to the administrators of other libraries to supplement its deficiencies, without insisting upon too rigid a uniformity of method, which could not be enforced.

While the project for a universal catalogue has remained in suspense, another catalogue has been silently growing up in print, far enough indeed from universality, but approaching it more closely than any other work of the kind. Commenced in I88x, and likely, if the Treasury grant is continued, to be completed at or a little before the close of the century, the printed Museum catalogue will be the register of about a million distinct publications. If its contents do not comprise a majority of the books existing in the world, they undoubtedly comprise a very great majority of the books which it is really

\footnotetext{
' Communicated to the Fifteenth Annual Meeting of the Library Association, Paris, September, 1892.
} 
important to catalogue. My recommendation to those who desiro to see a universal catalogue-as all do in theory-is to accept this confessedly imperfect catalogue as a temporary substitute, and labour to perfect it by the co-operation of the principal libraries throughout the world, not by reconstruction, which would introduce confusion and delay the undertaking indefinitely, but by the simple addition of such books in their possession as the Museum catalogue does not embrace. This would further involve the establishment of some central authority to edit these accessions, either incorporated with the Museum catalogue or separately, as circumstances might prescribe.

Even the Museum catalogue, however, is at present indequate to provide a basis for a universal catalogue, for the reason that it is in comparatively few hands. If general co-operation towards perfecting it is to be invited, it must be widely disseminated. It must be reprinted, and distributed gratuitously to all important libraries. It is, moreover, defective in its published form (not in the copy used in the Reading-Room), even as regards the contents of the Museum itself, on account of the number of accession titles which will have been steadily accumulating during the eighteen or nineteen years of its passage through the press. A large portion of these have been absorbed during the printing ; an equal number, perhaps, are excluded by the publication of the volume of catalogue before the appearance of the book. Letter B, therefore, is more complete than A, C than B, and so on. From the point of view of the universal catalogue, reprinting is thus an absolute necessity. It should take place at the earliest practicable date after the completion of the catalogue. The Government cannot be reasonably expected to provide the funds without strong pressure from public opinion, and it is partly in the hope of stimulating this opinion that I have ventured these observations. But if the universal catalogue is to be anything more than a fair vision, we must do more than stimulate others, we must organise ourselves. We must know what libraries throughout the civilised world would be ready, upon receiving a copy of the republished Museum catalogue, to supplement its deficiencies by furnishing the titles of such of their own books as are not to be found there. We must establish a central committee or committees to take charge of such titles, to cancel the innumerable duplicates, to reduce the others to approximate conformity with the rules on which the basis catalogue has been 
executed. We must have learned to what extent pecuniary assistance to small or over-worked libraries may be necessary, and have considered how to provide it. We must have determined whether the general catalogue is to embrace that of the Museum or to be merely supplementary, and in either case have framed some estimate of the probable expense, and of the means of meeting it. We must have decided some most important questions, as, for instance, whether pamphlets, newspapers, public documents, should be included, whether oriental books, to what extent cross references should be allowed, if admitted at all. These points and many others cannot be settled without active intercommunication among librarians, and when I consider the attendant difficulties, I own I am not sanguine that the project will have matured by the time that the Museum catalogue is in print.

When, however, the difficulties of organisation have been at length overcome, when the Museum catalogue is actually in the hands of the directors of all important libraries, and the task of supplying its deficiencies is being steadily prosecuted in a hundred different places, when the editorial committee is fairly engaged upon its task of revision and incorporation, and public sympathy has been fully enlisted, as would ere long assuredly be the case, the record of the world's literature which now may seem to many an utopian project, will have been brought within reach. In thus carrying it out we should have effected an object of still greater importance-the establishment of an universal literary registry, whose developments and ramifications it is impossible to predict. Such an institution is hardly likely to come into being without the tangible inducement of an universal catalogue, and it is on this account, quite as much as its own, that an universal catalogue is desirable. The organisation created to effect it would not be allowed to perish, but would be maintained for objects more important still. All these possibilities, however, will remain but visions unless they are based upon the firm ground of some actually existing catalogue, which may serve as a stepping-stone to the ideal catalogue of the future.

Cateris paribus, there can be no duubt that the biggest catalogue must be the best, and it is on this ground, and not from any claim of superiority of execution, that I venture to recommend the Museum catalogue as this n'cessary basis and stepping-stone, and to affirm that the problem of makin: an universal catalogue will be greatly simplitice it it is conceived as the 
problem of supplementing the deficiencies of the most extensivepartial catalogue we possess at present. The subject is one eminently suitable for consideration at the present conference, which, as the first ever held upon the Continent, possesses stronger claims to an international character than any of its predecessors.

Richard Garnett.

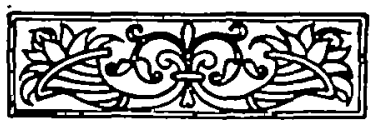

